\title{
Teachers' perceptions and readiness toward the implementation of virtual learning environment
}

\author{
Ana Haziqah A Rashid ${ }^{1}$, Nurbiha A Shukor ${ }^{2}$, Zaidatun Tasir ${ }^{3}$, Kew Si Na \\ ${ }^{1}$ Department of Human Resource Deveopment, School of Human Resource Development and Psychology, Faculty of \\ Social Sciences and Humanities, Universiti Teknologi Malaysia, Malaysia \\ ${ }^{2,3}$ Department of Science, Mathematics and Creative Multimedia, School of Education, Faculty of Social Sciences and \\ Humanities, Universiti Teknologi Malaysia, Malaysia \\ ${ }^{4}$ Language Academy, Faculty of Social Sciences and Humanities, Universiti Teknologi Malaysia, Malaysia
}

\begin{tabular}{l} 
Article Info \\
\hline Article history: \\
Received Sep 10, 2020 \\
Revised Jan 20, 2021 \\
Accepted Feb 6, 2021 \\
\hline
\end{tabular}

\section{Keywords:}

Online learning

Teachers' perceptions

Teachers' readiness

Technology acceptance model

Virtual learning environment

\begin{abstract}
The current trend of education is towards the implementation of technology in teaching in order to attract the attention of 21 st century learners whereby teachers need to adopt technology-enhanced environment such as the Virtual Learning Environment (VLE) in their teaching. This study aims to investigate the teachers' perceptions and tendency to use VLE as a tool for teaching. The teachers' perceptions were investigated based on the main constructs of the Technology Acceptance Model (TAM). The respondents were 178 teachers in southern state of Malaysia. The data were collected using a questionnaire and it is validated through the use of Rasch model. The finding was found that the teachers were moderately ready to use VLE and they moderately accepted the implementation of the VLE (mean $=3.67$ and 3.65). Besides that, the teachers felt that the VLE was useful (mean=3.58) and was easy to use (mean=3.34). It was also found that $84.2 \%$ of the teachers' acceptance was influenced by the teachers' readiness, and the teachers' perceptions of the usefulness and ease of using the VLE in teaching. Therefore, it can be concluded that Malaysian teachers has intention to use VLE in their teaching. The use of VLE can improve the innovative way of teaching that can increase students' interest in constructing knowledge through their learning process.
\end{abstract}

This is an open access article under the CC BY-SA license.

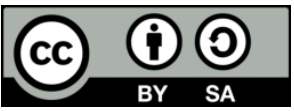

\section{Corresponding Author:}

Ana Haziqah A Rashid

Department of Human Resource Development

Faculty of Social Science and Humanities

Universiti Teknologi Malaysia

81310 Skudai, Johor, Malaysia

Email: anahaziqah@utm.my

\section{INTRODUCTION}

The Virtual Learning Environment (VLE) is one of the applications of information and communications technology (ICT) that can be used for teaching. The term of "virtual education" or "virtual learning" refers to the instruction in an online learning environment where teachers and students are separated by time or space, or both, and the teacher provides course content through the course management applications (e.g. e-learning or sharing portals), multimedia resources, the internet and video conferencing [1]. Students receive the content from teacher and communicate with the teacher via the same technologies and not in face to face setting [2,3]. A VLE is defined as a computer-based environment that is a relatively open system, allowing interactions and encounters with other participants and providing access to a wide 
range of resources [4]. In addition, Wilson [4] also stated that a VLE is different from the computer microworld where students individually enter a self-contained computer-based learning environment, and the classroom-based learning environment where various technologies are used as tools to support the classroom activities. By using a VLE, the learning process is no longer an individual endeavour, but can incorporate and leverage many-to-many relationships among learners and instructors [1]. This aspect was highlighted by Martins \& Kellermanns [5]; and Raman \& Rathakrishnan [6] who stated that a VLE can improve communication efficiency, for both teachers and students, as well as among students.

Besides that, a VLE application provides tools for assessment, communication, uploading of content, returning of students' work, administration of student groups, distributing questionnaires, tracking tools, wikis, blogs, chats, forums and many more purposes over the internet [7]. All the functions of a VLE application are useful for both teachers and students to use in the teaching and learning process. However, technology such as a VLE application will only be useful when a person has the willingness and is prepared to use it. Under such circumstances, teachers' willingness and perceptions of using VLE applications in teaching are very important to eventually guide and encourage students to use VLE technologies for teaching and learning purposes [8-10].

Although VLE provides many advantages to the users, a computer system cannot improve a user's performance if the the user do not have the intention to utilised it [11]. The Technology Acceptance Model (TAM) which rooted from Theory of Reasoned Action (TRA) proposes that the perceived usefulness and perceived ease of use of a technological tools are the major determinants of its utilisation. The tendency of people to use an application depends on their belief that the application will improve their work performance. Davis, et al. [12] used TAM to investigate why users accept or reject IT tools and how user acceptance is influenced by system characteristics. The TAM specifies the casual relationships between system design features, perceived usefulness, perceived ease to use, and attitude toward using and actual usage behaviour. The TAM has also been proven as a theoretical model that helps to explain and predict users' behaviour when interacting with IT [13-15]. Many researchers have begun to use TAM in studies on how to predict users' acceptance towards new technology and investigate how people adopt e-learning and VLEs [16]. Lee, et al. [17] used the TAM to examine and evaluate students' preparation and acceptance of a newlydeveloped VLE. Lee, et al. [17] also stated that the perceived usefulness and perceived easiness constructs in the TAM are influenced by external variables and will influence the attitudes towards using IT and the actual use of IT. In this context, the teachers' tendency to implement VLE was highly depend on their perception. Then, the teachers' perception can help in determining if the effectiveness of VLE implementation in teaching. Consequently, when a new technology like VLE is being integrated into the education system, the perceived usefulness, ease of use and teachers' level of readiness and acceptance should be investigated carefully. Failure to determine its usefulness and teachers' readiness will lead to the waste of energy and efforts to implement ICT in education especially in a developing country like Malaysia.

The Malaysian system of education consists of three basic stages, namely, primary and secondary education, post-secondary education and tertiary education [18]. Many research studies have been conducted on the ICT usage in Malaysian education in these three stages. Each stage involves different types of ICT tools implementation. For example, Lau and Sim [19] conducted a study to explore the extent of ICT adoption among secondary school teachers in Malaysia. The statistics from their study showed that school teachers used ICT for teaching and instructional support (75\%) and for classroom management activities (49\%) [19]. The ICT applications that were usually used by teachers in school were: teaching courseware, presentation tools, internet browsing, spreadsheets, visualising tools, hypermedia/multimedia, simulation programs and online demos [19]. Another study by Hoque, et al. [20] investigated the level of ICT facility usage among Malaysian school teachers, and the findings reveals that a large number of teachers (72\%) used ICT facilities for playing games and having fun, while $68 \%$ used ICT to help them with school and administrative work. These findings indicated that teachers were using ICT for leisure, personal use and for working purposes. They had also begun to become familiar with the use of ICT in their daily lives. However, the implementation of online element in the technology usage among Malaysian teachers such as VLE is still lacking. This is mostly because of the lack of ICT literacy skill among teachers [21-23].

To empower ICT in Malaysian education, Malaysian government has come out with their plan in the Malaysia Education Blueprint (2013-2025). One of the objectives being highlighted in this blueprint is to use ICT in enhancing the quality of education in Malaysia especially the self-directed learning and distance learning. This type of learning needs to have the flexibility of time and location for the students as well as the interactivity of the learning content. In fact, this objective is also aligned with the worldview of quality education as stated in one of the goals of Sustainable Development Goals (SDGs) [24]. In line with that, Malaysian government has initiated the usage of VLE. In relation to that, it is important to nurture the skills of using VLE in Malaysian teachers to ensure that they are prepared to shift their ways of teaching. However, 
having the skills to use VLE did not ensure the teachers have intention to use VLE in their teaching. Hence, there is a gap to determine whether Malaysian teachers has the intention to use VLE in their teaching process.

This study aimed to investigate the teachers' perception and readiness towards the implementation of VLE. The following are the detail objective of this study: 1) To identify the teacher's perceptions to use VLE based on the level of readiness; 2) To examine the teachers' perceptions to use VLE based on teachers' acceptance, perceived usefulness and perceive ease of use; 3) To identify the relationship between teachers' teaching experience and their experience using VLE; and 4) To determine the effect of teachers' perception on VLE toward teachers' acceptance.

\section{RESEARCH METHOD}

The population of this study was the teachers in primary and secondary schools who had been implementing VLE as a tool for teaching. The respondents in this study were selected through purposive sampling involving the teachers using VLE. The reason to use purposive sampling is not all schools in the southern state of Malaysia have used VLE in teaching. Also, the selected respondents were teachers who had been exposed to the VLE and learnt the ways of using the VLE for more than one month. The respondents were 178 teachers in southern state of Malaysia. In this study, the quantitative data were collected using a set of questionnaire. The questionnaire was adapt from Davis [11]; Soh [25]; and Lee, et al. [26] being revised to suite with the scope and respondent of the study. Then, it is being validated by the content expert and tested to 30 school teachers. After that, the Cronbach Alpha of the questionnaire was calculated using the Rasch Model. Rasch model was used to obtain the reliability based on each item and person of the questionnaire to make sure it fit to the respondent and the scope of study since it is a robust method in identifying reliability of a questionnaire. The Cronbach Alpha obtained from the Rasch model was 0.98 which is considered as reliable. The Rasch model also calculated the value of person reliability and item reliability, which were 0.97 and 0.83 respectively. In this questionnaire, a Five-point Likert scale were used which include 1-5 response scale (strongly disagree to strongly agree). The questionnaire used in this study consists of six sections as shown in Table 1.

Table 1. Number of items and sections in the questionnaire

\begin{tabular}{lc}
\hline & Sections \\
\hline Section A: Demographic information & Number of items \\
Section B: Teachers' perceptions of using VLE as one of the tools for teaching based on the level of readiness & 3 \\
Section C: Teachers' perceptions of using VLE based on their level of acceptance & 20 \\
Section D: Teachers' perceptions of the usefulness of the VLE & 9 \\
Section E: Teachers' perceptions of the VLE's ease of use & 13 \\
Section F: Suggestions and recommendations & 14 \\
\hline
\end{tabular}

\section{RESULTS}

\subsection{Respondents' demographic information}

In this study, the demographic information collected included the respondent's level of computer literacy, teaching experience and experience of using VLE. The findings are shown in Table 2. The highest percentage of computer literacy which means there are able to use Microsoft Office efficiently with $93.3 \%$ compared to internet browsers and social network sites which are $91.6 \%$ and $84.8 \%$, respectively. The results indicated that almost all the teachers were computer literate and had no problem to implement VLE in teaching. Besides that, most of the teachers in this research had long teaching experience, with $52.2 \%$ of the respondents having teaching experience of 10 years and more. Meanwhile, most of the respondents $(43.3 \%)$ had experience in implementing VLE for between six months and nearly one year. This shows that Malaysian teachers actually have been implementing VLE in their teaching for quite a while.

Further investigation was conducted to identify the relationship between the respondents' computer literacy, teaching experience and experience using VLE. Table 3 shows that there was a significant relationship between the respondents' teaching experience and experience using VLE $(r=0.182, p<0.05)$. This indicates that the respondents' experience in using VLE was influenced by their year of teaching experience. There was no significant relationship between computer literacy and the experience in using VLE. This shows that teachers who had more experience in teaching were not necessarily the teachers' with high computer literacy skills and vice versa. 
Table 2. Demographic information

\begin{tabular}{clcc}
\hline \multicolumn{1}{c}{ Section } & \multicolumn{1}{c}{ Item } & Frequency & Percentage (\%) \\
\hline Computer literacy & Microsoft office & 166 & 93.3 \\
& Internet browser & 163 & 91.6 \\
& Social networking sites & 151 & 84.8 \\
Teaching experience & 1-2 years & 17 & 9.6 \\
& 3-5 years & 26 & 14.6 \\
& 6-10 years & 42 & 23.6 \\
& 10 years and above & 93 & 52.2 \\
Experience using VLE & 1 month & 53 & 29.8 \\
& 3 months & 48 & 27.0 \\
& Others (6 months to 1 year) & 77 & 43.3 \\
\hline
\end{tabular}

Table 3. Relationship between respondents' computer literacy, teaching experience and experience using VLE

\begin{tabular}{|c|c|c|c|c|}
\hline & & Computer literacy & $\begin{array}{l}\text { Teaching } \\
\text { experience }\end{array}$ & $\begin{array}{c}\text { Experience using } \\
\text { VLE }\end{array}$ \\
\hline \multirow[t]{2}{*}{ Computer literacy } & Pearson correlation & 1 & 0.98 & -0.72 \\
\hline & Sig. (2-tailed) & - & 0.192 & 0.337 \\
\hline \multirow[t]{2}{*}{ Teaching experience } & Pearson correlation & 0.98 & 1 & $0.182 *$ \\
\hline & Sig. (2-tailed) & 0.192 & - & 0.015 \\
\hline \multirow[t]{2}{*}{ Experience using VLE } & Pearson correlation & -0.72 & $0.182 *$ & 1 \\
\hline & Sig. (2-tailed) & 0.337 & 0.15 & - \\
\hline
\end{tabular}

*Correlation is significant at the 0.05 level (2-tailed)

\subsection{Teachers' Perceptions of Using VLE}

Table 4 shows the findings from descriptive analysis of the teachers' perception of using VLE. The highest mean for teachers' perception in using VLE was the teachers' readiness (mean=3.67). However, the result reveals that the teachers' readiness to use VLE as a teaching tool was moderate. The teachers were probably not ready to use all the functions in VLE. On the other hand, the teachers' perception on their level of acceptance was moderate (mean=3.65) which was similar to the teachers' perception on usefulness with mean=3.58. This implies that some of the teachers were able to accept the implementation of VLE and felt that VLE is useful in their teaching process while some of them were not. The lowest mean of the teachers' perception on using VLE is the ease of use with the mean=3.34.

Table 4. Descriptive analysis of the teachers' perception of using VLE

\begin{tabular}{ccc}
\hline Teachers' perception of using VLE & Mean & SD \\
\hline Level of readiness & 3.67 & 0.89 \\
Level of acceptance & 3.65 & 0.85 \\
Usefulness & 3.58 & 0.85 \\
Ease of use & 3.34 & 0.87 \\
\hline
\end{tabular}

$* \mathrm{SD}=$ standard deviation

\subsection{Relationship between teachers' perception in using VLE based on their teaching experience and their experience using VLE}

The relationship between the teachers' perceptions in using VLE based on their teaching experience and experience using VLE was examined using Pearson correlation. The findings were shown in Table 5. Based on the findings, no significant relationship was shown between teaching experience and teachers' perception in using VLE. Meanwhile, there is significant but weak relationship between the experience using VLE with the teachers' level of readiness $(r=0.148, \mathrm{p}<0.05)$, the teachers' acceptance $(\mathrm{r}=0.158, \mathrm{p}<0.05)$ and the ease of use $(r=0.161, p<0.05)$. The findings imply that teachers' teaching experience has lack influence on teachers' perception in using VLE. However, the teachers' experience using VLE do affect the teachers' readiness, acceptance and ease of use towards VLE in teaching. 
Table 5. Correlation of teachers' perception in using VLE based on their teaching experience and teachers'

\begin{tabular}{llcccc}
\multicolumn{7}{c}{ experience using VLE } \\
\hline Teaching experience & & Level of readiness & Teachers' acceptance & Usefulness & Ease of use \\
& Pearson correlation & -0.081 & -0.066 & -0.098 & -0.113 \\
Experience using VLE & Sig. (2-tailed) & 0.282 & 0.380 & 0.191 \\
& Pearson correlation & $0.148^{*}$ & $0.158^{*}$ & 0.133 \\
& Sig. (2-tailed) & 0.049 & 0.035 & $0.161^{*}$ & 0.065 \\
\hline
\end{tabular}

*Correlation is significant at the 0.05 level (2-tailed)

\subsection{Effect of teachers' perception on VLE toward teachers' acceptance}

The multiple regression analysis was conducted to identify the effect of teachers' acceptance in VLE that based on the teachers' level of readiness, teachers' perceptions of the usefulness and ease of use. Table 6 displays the results obtained from the multiple regression analysis in SPSS. The R square value showed that $84.2 \%$ of the teachers' acceptance was influenced by the teachers' readiness, teachers' perceptions of the usefulness and ease of using the VLE in teaching.

Table 6. Effect of teachers' perception on VLE toward teachers' acceptance.

\begin{tabular}{ccccc}
\hline Model & $\mathrm{R}$ & $\mathrm{R}$ square & Adjusted R square & Std. error of the estimate \\
\hline 1 & $0.918^{\mathrm{a}}$ & 0.842 & 0.839 & 2.72032 \\
\hline a. Predictors: (Constant), total ease of use, total readiness, total usefulness
\end{tabular}

b. Dependent Variable: Total Acceptance

\section{DISCUSSION}

This study presented that Malaysian teachers have a good skill in computer literacy which they did not have many problems in using basic ICT skills including Microsoft Office, internet browsers and social networking sites. The teachers also have been implementing VLE in their teaching for quite a while. Despite that, this study has found that some of the teachers feels that they still struggling in handling VLE in their classes whereby more trainings and practices might be needed to make them familiar in using all the tools in VLE. This finding is aligned with the research conducted by Li, et al. [27].

This study also found that the teaching experience and their experience in using VLE not likely to make them accept the usage of VLE for teaching. This is aligned with the finding found by Voogt \& McKenney [28]; and Awang et al. [29] which teachers are still having difficulty in integrating technology in teaching even though they have many years of experience in teaching.However, this study demonstrate that teachers' acceptance are based on their readiness, perceptions of the usefulness and ease of using the VLE in teaching. This finding is also echoed by Joo, et al. [30]; and Akar [31] who reported that the teachers' acceptance is based on their own belief and readiness to use as well as the technological part itself such as the ease of use and usefulness. Hence, the teacher will develop the intention to use technological tools such as VLE in their teaching which aligned with TAM.

\section{CONCLUSION}

Based on the results, it can be concluded that Malaysian teachers can modereately ready and accept the implementation of VLE in their teaching. This is because the teachers find that the VLE is useful and easy to use. The investigation carried out in this study led to various findings on teachers' perceptions of usage of VLE. Technology acceptance model (TAM) is a popular model used to identify the perception of teachers in using technology in teaching. Based on the model, it can be observed that the teachers are ready to use the technology when they find that it is useful and easy to use. TAM also predict that the usefulness and ease of use will lead to the behavioural intention to use before the actual use will happen. The use of VLE can improve the innovative way of teaching that can increase students' interest in constructing knowledge through their learning process. Despite that, the finding from this study only limited to the use of VLE in teaching. Further study should be done to explore more on the potential of other types of technology usage for school teachers.

\section{REFERENCES}

[1] G. Piccoli, R. Ahmad, and B. Ives, "Web-based virtual learning environments: A research framework and a preliminary assessment of effectiveness in basic IT skills training," MIS Quarterly, vol. 25, no. 4, pp. 401-426, 2001, doi: $10.2307 / 3250989$. 
[2] K. Kurbel, "Virtuality on the Students' and on the Teachers' sides: A Multimedia and Internet based International Master Program," in Proc. 7th Int. Conf. Technol. Supported Learn. Train., 2001, pp. 133-136.

[3] C. E. Parsons, et al., "Designing technology tools to support engagement in mindfulness-based interventions: an analysis of teacher and student experiences," Digit. Heal., vol. 5, 2019, doi: 10.1177/2055207619868550.

[4] B. G. Wilson, Constructivist learning environments: Case studies in instructional design. Educational Technology, 1996.

[5] L. L. Martins and F. W. Kellermanns, "A model of business school students' acceptance of a web-based course management system," Acad. Manag. Learn. Educ., vol. 3, no. 1, pp. 7-26, 2004.

[6] A. Raman and M. Rathakrishnan, "FROG VLE: Teachers' technology acceptance using utaut model," Int. J. Mech. Eng. Technol., vol. 9, no. 3, pp. 529-538, 2018.

[7] M. M. Chan, R. B. Plata, J. A. Medina, C. Alario-Hoyos, and R. H. Rizzardini, "Modeling educational usage of cloud-based tools in virtual learning environments," IEEE Access, vol. 7, pp. 13347-13354, 2018.

[8] M. L. Cheok, S. L. Wong, A. F. Ayub, and R. Mahmud, "Teachers' Perceptions of E-Learning in Malaysian Secondary Schools.," Malaysian Online J. Educ. Technol., vol. 5, no. 2, pp. 20-33, 2017.

[9] C. M. Shen and S. A. Shariff, "Apply UTAUT model for understanding the teacher perceptions using frog VLE," in Postgraduate Annual Research On Informatics Seminar (Paris 2016), 2016.

[10] N. Harding, "The Digital Turn: staff perceptions of the virtual learning environment and the implications for educational developers," Irish J. Technol. Enhanc. Learn., vol. 3, no. 2, pp. 58-76, 2018.

[11] F. D. Davis, "Perceived usefulness, perceived ease of use, and user acceptance of information technology," MIS Q., vol. 13, no. 3, pp. 319-340, 1989.

[12] F. D. Davis, R. P. Bagozzi, and P. R. Warshaw, "User acceptance of computer technology: a comparison of two theoretical models," Manage. Sci., vol. 35, no. 8, pp. 982-1003, 1989.

[13] R. Scherer, F. Siddiq, and J. Tondeur, "The technology acceptance model (TAM): A meta-analytic structural equation modeling approach to explaining teachers' adoption of digital technology in education," Comput. Educ., vol. 128, pp. 13-35, 2019.

[14] R. Alotaibi, L. Houghton, and K. Sandhu, "Factors influencing users' intentions to use mobile government applications in Saudi Arabia: TAM applicability," Int. J. Adv. Comput. Sci. Appl., vol. 8, no. 7, pp. 200-211, 2017.

[15] H.-H. Yang and C.-H. Su, "Learner behaviour in a MOOC practice-oriented course: in empirical study integrating TAM and TPB," Int. Rev. Res. Open Distrib. Learn. IRRODL, vol. 18, no. 5, pp. 35-63, 2017.

[16] H. M. Selim, "An empirical investigation of student acceptance of course websites," Comput. Educ., vol. 40, no. 4, pp. 343-360, 2003.

[17] M. K. O. Lee, C. M. K. Cheung, and Z. Chen, "Acceptance of Internet-based learning medium: the role of extrinsic and intrinsic motivation," Inf. Manag., vol. 42, no. 8, pp. 1095-1104, 2005.

[18] Ministry of Education Malaysia, "Malaysia Education Blueprint 2013-2025," Education, vol. 27, no. 1, pp. 1-268, 2013.

[19] B. T. Lau and C. H. Sim, "Exploring the extent of ICT adoption among secondary school teachers in Malaysia," Int. J. Comput. ICT Res., vol. 2, no. 2, pp. 19-36, 2008.

[20] K. E. Hoque, A. Z. A. Razak, and M. F. Zohora, "ICT utilization among school teachers and principals in Malaysia," Int. J. Acad. Res. Progress. Educ. Dev., vol. 1, no. 4, pp. 17-34, 2012.

[21] S. Ghavifekr, T. Kunjappan, L. Ramasamy, and A. Anthony, "Teaching and Learning with ICT Tools: Issues and Challenges from Teachers' Perceptions," Malaysian Online J. Educ. Technol., vol. 4, no. 2, pp. 38-57, 2016.

[22] K. Kamaruddin, C. A. C. Abdullah, and M. N. Idris, "Integrating ICT in teaching and learning: A preliminary study on Malaysian private preschool," Int. J. Acad. Res. Bus. Soc. Sci., vol. 7, no. 11, pp. 1236-1248, 2017.

[23] E. A. Tokareva, et al., "Innovation and communication technologies: Analysis of the effectiveness of their use and implementation in higher education," Educ. Inf. Technol., vol. 24, no. 5, pp. 3219-3234, 2019.

[24] United Nations, "Sustainable Devlopment Goals," 2020. [Online]. Available: https://www.un.org/sustainabledevelopment/

[25] P. L. Soh, "Students' Readiness and Perceptions towards Mobile Learning and their Acceptance in Adopting Mobile Learning Platform as Learning Tool and Communication Tool," UTM Thesis, vol. 66, pp. 37-39, 2012.

[26] J. Lee, N. L. Hong, and N. L. Ling, "An analysis of students' preparation for the virtual learning environment," Internet High. Educ., vol. 4, no. 3-4, pp. 231-242, 2002.

[27] Y. Li, et al., "Predicting high school teacher use of technology: Pedagogical beliefs, technological beliefs and attitudes, and teacher training," Technol. Knowl. Learn., vol. 24, no. 3, pp. 501-518, 2019.

[28] J. Voogt and S. McKenney, "TPACK in teacher education: Are we preparing teachers to use technology for early literacy?" Technol. Pedagog. Educ., vol. 26, no. 1, pp. 69-83, 2017.

[29] H. Awang, et al., "Teachers' intention to continue using Virtual Learning Environment (VLE): Malaysian context," JOTSE, vol. 8, no. 4, pp. 439-452, 2018.

[30] Y. J. Joo, S. Park, and E. Lim, "Factors influencing preservice teachers' intention to use technology: TPACK, teacher self-efficacy, and technology acceptance model," J. Educ. Technol. Soc., vol. 21, no. 3, pp. 48-59, 2018.

[31] S. G. M. Akar, "Does it matter being innovative: Teachers' technology acceptance," Educ. Inf. Technol., vol. 24, no. 6, pp. 3415-3432, 2019. 